\title{
Polyembryony in citrus: does the largest embryo in the seed develop a nucellar
} seedling?

\author{
Elisa del Carmen Martínez-Ochoa ${ }^{1}$, Itzel Villegas-Velázquez ${ }^{1 \oplus}$, Baldomero Alarcón-Zúñiga ${ }^{2}{ }^{\oplus}$, Víctor Arturo González-Hernández ${ }^{1 \oplus}$, \\ Angel Villegas-Monter ${ }^{*} \odot$
}

\author{
${ }^{1}$ Colegio de Postgraduados/PREGEP - Fisiología Vegetal, \\ Campus Montecillo, km 36.5, Carretera México-Texcoco - \\ 56230 - Texcoco de Mora - México. \\ 2Universidad Autónoma Chapingo - Depto. de Zootecnia - \\ Lab. de Genética Molecular, km. 38.5, Carretera México- \\ Texcoco, Texcoco de Mora - México. \\ *Corresponding author <villema53@gmail.com>
}

Edited by: Leonardo Oliveira Medici

Received March 04, 2020

Accepted July 13, 2021
ABSTRACT: A generalized concept in the Citrus genus is that highly polyembryonic varieties produce only a small number of hybrids. Small zygotic embryos congregate primarily near the micropyle, while nucellar embryos organize near or away from the micropyle. In the present study, the authors determined the number of polyembryonic seeds, embryos per seed, and the largest embryo (LE) position in five citrus cultivars: C35 citrange, Volkamer lemon, Amblycarpa mandarin, Minneola tangelo, and Valencia orange. The percentage of nucellar seedlings obtained exclusively from the LE per seed was then calculated. The polyembryony percentage varied largely between genotypes, from 65 to $98 \%$, and the mean number of embryos ranged from 2.9 to 4.6 . The chalaza contained up to $87 \%$ of the LE. Out of 30 primers, 17 Simple sequence repeats [SSRs] (AG14, ATC09, CAT01, CCSM147, CCSM18, CCSM13, CCSM4, F2, F4, F6, GT03, TAA41, TAA45, TAA1, F7, F11 and TAA52) identified nucellar plants identical to the female parent (genetic similarity index [GSI] value $\geq 0.95$ ). This study establishes for the first time the relationship between the sexual or asexual origin of seedlings derived from LE embryos isolated from seeds and the SSR primers described above. While the five citrus cultivars had high polyembryony levels, $30 \%$ of the resulting plants differed from the female parent in C35 Citrange, $45 \%$ in Volkamer lemon, $15 \%$ in Amblycarpa mandarin, $15 \%$ in Valencia orange, and $45 \%$ in Minneola tangelo. The largest seedling is not always nucellar: in the five citrus species studied, the LE produces 55 to $85 \%$ of the nucellar embryos.

Keywords: Apomictic Citrus genotypes, SSR, polyembryony, seedlings different from the female parent, embryo origin

\section{Introduction}

Polyembryony is a type of sporophytic apomixis commonly found in citrus species, except in Citrus medica L., Citrus grandis Tanaka. Citrus clementina "Tanaka, and in a number of mandarin hybrids (Aleza et al., 2010; Ribeiro et al., 1999). Some researchers have attempted to link the embryo characteristics to their sexual or asexual origin. For example, in the mature Citrus reshni Hort. ex Tanaka seed, the smallest embryos developing at the micropyle end are usually considered zygotic embryos (Andrade-Rodríguez et al., 2005), while the nucellar embryos may develop near or away from the micropyle (Kishore et al., 2012). However, in apomictic citrus, developing nucellar embryos were found to promote early embryogenesis and competition for endosperm nutrients among embryos (Wakana and Uemoto, 1988). Furthermore, the initial development of both zygotic and nucellar embryos is inhibited in the chalazal region (Koltunow et al., 1995; Wakana and Uemoto, 1988), and consequently, both embryos grow preferentially near the micropyle end.

Different researchers claim that cultivars showing high polyembryonic percentages are less likely to develop hybrid seedlings since their zygotic embryos will not survive under field conditions. In contrast, the largest nucellar embryos might produce vigorous seedlings (Aleza et al., 2010; Bastianel et al., 1998; Soares-Filho et al., 2000). Thus, the selection of polyembryonic genotypes is preferred for the promotion of vegetative or clonal propagation (Andrade-Rodríguez et al., 2004; Duarte et al., 2013; Passos et al., 2006). Additionally, the occurrence and germination of the two embryo types depend on multiple factors like genotype, climate, pollinators, fertilization, seed development stage, and other plant physiological conditions (Kishore et al., 2012; Rao et al., 2008; Yildiz et al., 2013).

Microsatellites (SSRs or repeated single sequences) are efficient molecular markers that identify nucellar and zygotic seedlings in citrus seeds obtained either through self-pollination or crosspollination, even with low heterozygosity levels. SSRs have identified cross-hybrids between citrus species (Carrillo-Medrano et al., 2018; Ruiz et al., 2000; Rao et al., 2008; Yildiz et al., 2013). These researchres found no association between the sexual or asexual origin of the seedling and the embryo in the seed.

This study aimed to identify nucellar seedlings produced by female parents in seedlings obtained from the largest embryo in seeds for two citrus cultivars (Valencia orange and Minneola tangelo) and three rootstocks (C-35 citrange, Volkamer lemon, and Amblycarpa mandarin) by using 30 microsatellites as SSR markers. 


\section{Materials and Methods}

\section{Plant material}

The plants studied included two citrus cultivars, Valencia orange (Citrus sinensis (L.) Osbeck) and Minneola tangelo (C. paradisi Macf. x C. reticulata Blanco), and three citrus rootstocks: C-35 citrange (C. sinensis x Poncirus trifoliata), Volkamer lemon (C. volkameriana Pasq.) and Amblycarpa mandarin (C. amblycarpa (Hassk.) Ochse). From two fruit production cycles, 2013-2014 and 2014-2015, 100 viable seeds of mature openpollinated fruits were selected from each cultivar. These seeds were used to determine the percentage of polyembryony, the number of embryos per seed, and the largest embryo position in each seed. In the 2014-2015 cycle, the largest embryos were extracted from 20 seeds and germinated in vitro for molecular analysis. All trees grew under the humid tropical conditions of Cazones, Veracruz, Mexico $\left(20^{\circ} 41^{\prime} \mathrm{N}, 97^{\circ} 19^{\prime} \mathrm{W}, 22\right.$ m.a.s.1.); $25^{\circ} \mathrm{C}$ average temperature; $82 \%$ average $\mathrm{RH}$.

\section{Polyembryonic seeds and their largest embryos}

Ten mature fruits from the five cultivars were sampled at random from each harvest, and their seeds removed for washing in $2 \%(\mathrm{v} / \mathrm{v})$ sodium hypochlorite with five drops of liquid detergent followed by stirring for $15 \mathrm{~min}$ to remove the mucilage in the seed coat. Ten seeds per fruit were then selected at random to complete a 100 viable-seed sample. The seed coat was then removed from each seed, and their embryos separated with a dissecting needle, tweezers, and a 10x stereomicroscope. The number of embryos per seed and the percentage of polyembryonic seeds were recorded (Figure 1). The binary code proposed by Kishore et al. (2012) was used to classify the seeds as follows: ' 0 ' for monoembryonic seeds (one embryo per seed) and ' 1 ' for polyembryonic seeds (two or more embryos per seed).

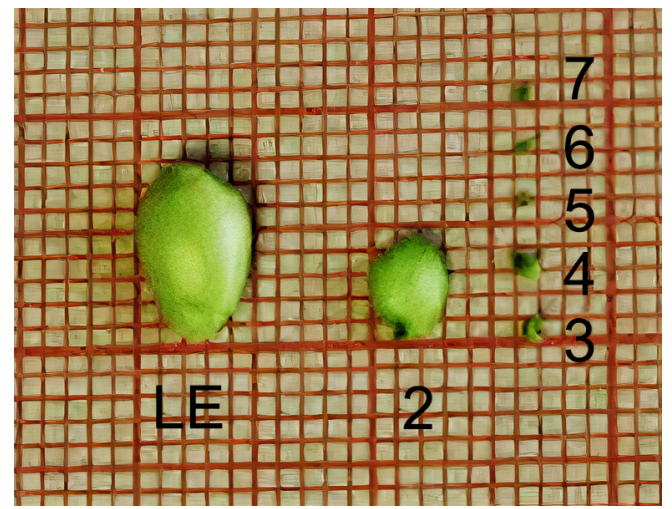

Figure 1 - Selection of the largest embryo (LE) within the seven embryos formed by an Amblycarpa mandarin fruit seed, shown on a millimetric scale. Ordered by size, the largest embryo was considered number one.
The largest embryo (LE) in each seed was separated, and when two embryos were of similar size, both were discarded to avoid uncertainty in the LE classification. The location of each LE was recorded with a binary code: ' 1 ' for the chalazal region (opposite the hilum) and '0' for the micropylar region.

The Shapiro-Wilk normality test on the number of polyembryonic seeds and the number of embryos per seed showed that data were not normally distributed. These statistical procedures were conducted using the PROC UNIVARIATE procedure in SAS (Statistical Analysis System, version 9.3). Thus, a non-parametric MannWhitney test was used for the purpose of comparing the two harvest cycles (2013-2014 and 2014-2015).

\section{Identification of nucellar seedlings}

In the 2014-2015 cycle, 20 mature seeds were selected at random and washed in $10 \mathrm{~g} \mathrm{~L}^{-1}$ of $\mathrm{Ca}(\mathrm{OH})_{2}$ solution for $10 \mathrm{~min}$. The seed coat was removed, and the seeds were disinfected with $2.6 \% \mathrm{NaOCl}$ (commercial sodium hypochlorite) for $5 \mathrm{~min}$ in a sterile environment. $\mathrm{NaOCl}$ was decanted, and the seeds rinsed three times with sterile distilled water. The integument was then removed, and the largest embryo (LE) per seed excised and sowed in test tubes $(25 \mathrm{~mm} \times 150 \mathrm{~mm})$ containing $10 \mathrm{~mL}$ of culture medium $\left(20 \mathrm{~g} \mathrm{~L}^{-1}\right.$ sucrose and $6 \mathrm{~g} \mathrm{~L}^{-1}$ agar-agar, $\mathrm{pH}$ 5.7). The LE were incubated in darkness at $24-26{ }^{\circ} \mathrm{C}$ for two weeks.

After germination, successful seedlings were sub-cultured into a culture medium containing 3.0 $\mathrm{mM} \mathrm{NH} \mathrm{NO}_{3}, 3.0 \mathrm{mM} \mathrm{KNO}{ }_{3}, 0.2 \mathrm{mM} \mathrm{Ca}\left(\mathrm{NO}_{3}\right)_{2}, 0.2$ $\mathrm{mM} \mathrm{KH} \mathrm{KO}_{4}$, and $0.1 \mathrm{mM} \mathrm{MgSO}$. Incubation room conditions were kept constant for approximately two months: the temperature at $24-26^{\circ} \mathrm{C}$ and $16 \mathrm{~h}$ of light at $30 \mu \mathrm{mol} \mathrm{m} \mathrm{m}^{-2} \mathrm{~s}^{-1}$ provided by white fluorescent tubes.

In vitro seedlings, 3 to $4 \mathrm{~cm}$ in length, were then grafted onto Volkamer lemon rootstocks to promote growth. Rootstocks were four to five months old. Both grafted parts were tied together with Parafilm, and the graft was covered with plastic bags to prevent dehydration. The plastic bag was removed four weeks later. Then grafted plants were stored in a greenhouse at $30-35{ }^{\circ} \mathrm{C}$ and $80-95 \%$ relative humidity for ten months.

Young leaves were collected from the grafted plants and the female parent from each citrus genotype. Sampled leaves were frozen at $-80{ }^{\circ} \mathrm{C}$, freeze-dried at $-47{ }^{\circ} \mathrm{C}$ for five days, and ground in a bead mill homogeniser. Approximately $100 \mathrm{mg}$ of tissue was collected. Leaf DNA was extracted according to the protocol by Sudheer et al. (2008), with the following modifications: the extraction solution contained $1 \mathrm{M}$ $\beta$-mercaptoethanol and chloroform:octanol (24:1), and was used for organic phase separation. DNA quality was assessed in $1.0 \%(\mathrm{w} / \mathrm{v})$ agarose stained with ethidium bromide $\left(10 \mathrm{mg} \mathrm{m} \mathrm{L}^{-1}\right)$ for $15 \mathrm{~min}$. The concentration and purity of DNA were quantified with an Ultravioletvisible spectrophotomer at 260/280 $\mathrm{nm}$ absorbance. 
The polymerase chain reaction (PCR) amplification of a specific segment of DNA by oligo sets was performed as recommended by Rao et al. (2008) in a thermocycler, without fluorescent markers. Table 1 shows the set of 30 microsatellites used in this research. The 'Touchdown' PCR program consisted of a cycle at $94{ }^{\circ} \mathrm{C}$ for $3 \mathrm{~min}$ for initial denaturation, followed by 10 cycles at $94{ }^{\circ} \mathrm{C}$ for $30 \mathrm{~s}$, annealing temperatures as defined for each primer for $30 \mathrm{~s}$ (Table 1 ), and $72{ }^{\circ} \mathrm{C}$ for $45 \mathrm{~s}$ for the extension. Next, the PCR continued with 33 cycles at $94{ }^{\circ} \mathrm{C}$ for $30 \mathrm{~s}$, followed at $51{ }^{\circ} \mathrm{C}$ for $30 \mathrm{~s}$ and $72{ }^{\circ} \mathrm{C}$ for $45 \mathrm{~s}$. The final PCR extension was at $72{ }^{\circ} \mathrm{C}$ for $30 \mathrm{~min}$. The PCR product was mixed with $6 \mu \mathrm{L}$ of loading buffer $(50 \mathrm{mM}$ Tris, $5 \mathrm{mM}$ EthyleneDiamine TetraAcetic acid (EDTA) pH $8,25 \%$ sucrose, and $0.2 \% \mathrm{w} / \mathrm{v}$ bromophenol blue) and analyzed by electrophoresis in a $14 \%$ polyacrylamide gel (acrylamide: $N, N^{\prime}$-methylbisacrylamide, 29:1). The gel was stained with $0.2 \% \mathrm{AgNO}_{3}$ A $1 \mathrm{~kb}$ molecular size marker was used. The running electrophoretic conditions were $190 \mathrm{~V}$ and $200 \mathrm{~mA}$ for $90 \mathrm{~min}$.

Identification of nucellar seedlings required analysis of DNA polymorphisms by comparing the SSR markers in these seedlings against the SSR markers in the female parent. Different amplicons were recognized as polymorphisms. Seedlings classified as genetically different from the female parent could be separated from nucellar seedlings by the different banding patterns (Rao et al., 2007).

The polymorphism information content (PIC) of each marker was calculated as described by Novelli et al. (2006). PIC expresses the ability of each marker to differentiate the origin of the seedlings. Furthermore, the genetic similarity index or GSI was used to identify nucellar seedlings (Mannen et al., 1993). This index was determined for individuals of all citrus genotypes by the formula GSI $=(2 p+q) / 2 N$, where $p$ is the number of identical alleles between two genotypes, $\mathrm{q}$ the number of different alleles between two individuals (heterozygous or heterozygous with null alleles), and $\mathrm{N}$ the total number of alleles analyzed. The standard error and the confidence interval (IC 0.95) were calculated using an SAS software program (Statistical Analysis System, version 9.3). The sample size for each cultivar was estimated with a confidence level of $95 \%$ (Holland, 2006; Wu et al., 2007).

When the GSI had a value $\geq 0.95$, the seedlings obtained from the largest embryo in each seed were identified as identical to the female parent and thus were classified as nucellar plants. Moreover, when the
GSI values were $<0.95$, they were classified as plants different from the female parent.

\section{Results}

\section{Polyembryonic seed and its largest embryo}

The percentage of polyembryonic seeds differed in the two cycles for C35, Amblycarpa, and Minneola, while Volkamer and Valencia showed no statistical differences (Table 2). The cycle did not affect the number of embryos per seed in C35, Volkamer, Amblycarpa, and Valencia, and the embryo number increased only in Minneola tangelo for the 2014-2015 period (Table 2). The percentage of large embryos located at the chalaza (PEC) reached $100 \%$ for Volkamer lemon, while PEC ranged between 87 and $93 \%$ for the other genotypes (Table 2).

\section{Identification of nucellar seedlings produced by the largest embryo in each seed of fruits harvested from the female parent}

The degrees of genetic similarity (nucellar) between progeny seedlings for each SSR primer and between all SSRs primers were determined and compared to the SSR bands produced by the female parent (Figure 2). Seventeen molecular markers (Table 3) detected nucellar seedlings and genetically different seedlings from the female parent (GSI < 0.95). These 17 primers generated 137 polymorphic bands. PIC values greater than 0.5 allowed for selection of certain markers, such as TAA 41 and F4, by high discrimination capacity (DeWoody et al., 1995). The mean genetic similarity and standard error among progenies varied from 0.95 ( $\mathrm{SE}=$ $0.03), 0.96$ (SE $=0.03)$, and $0.96(\mathrm{SE}=0.04)$ in $\mathrm{C} 35$ citrange, Amblycarpa mandarin, and Valencia orange, respectively, to 0.91 ( $\mathrm{SE}=0.04)$ in Volkamer lemon and Minneola tangelo. The sample size oscillated from ten in C35 citrange to 20 seeds for Minneola tangelo.

A unique, single SSRs primer could not identify all the seedlings. However, the discrimination capacity of the 17 selected primers allowed for the detection of seedlings different from the female parent as putative zygotic seedlings. The lack of the banding pattern of the male in the comparison prevented the identification of heterozygotic seedlings (thus named "putative zygotic seedlings"). In C35 citrange, $30 \%$ of the seedlings were classified as being different from the female parent, while they represented $45 \%$ in Volkamer lemon, $15 \%$

Table 1 - Annealing temperatures in 'Touchdown' PCR, with a decrease of $1^{\circ} \mathrm{C}$ for each amplification cycle.

\begin{tabular}{|c|c|}
\hline Annealing temperature & Primers \\
\hline $60-50{ }^{\circ} \mathrm{C}$ & 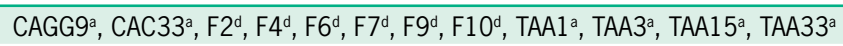 \\
\hline $58-48^{\circ} \mathrm{C}$ & 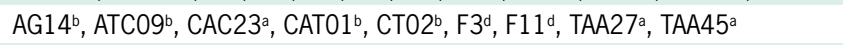 \\
\hline $56-46^{\circ} \mathrm{C}$ & 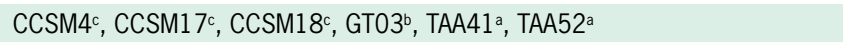 \\
\hline $54-44{ }^{\circ} \mathrm{C}$ & $\operatorname{CCSM}^{c}, \operatorname{CCSM}^{2} 3^{c}, \operatorname{CCSM} 147^{c}$ \\
\hline
\end{tabular}

aKijas et al. (1997), 'Barkley et al. (2006), cNovelli et al. (2006), dRao et al. (2008). 
in Amblycarpa mandarin, $15 \%$ in Valencia orange, and $45 \%$ in Minneola tangelo. Furthermore, the GSI values for nucellar seedlings ranged from $\geq 0.95$ to 1.0 . The percentages per genotype for this type of seedlings were $70 \%$ in C35 citrange, $55 \%$ in Volkamer lemon, $85 \%$ in Amblycarpa mandarin, $85 \%$ in Valencia orange, and $55 \%$ in Minneola tangelo (Table 4).

\section{Discussion}

\section{Polyembryonic seed frequency and largest embryo}

The percentage of polyembryonic seeds (PS) varied between genotypes and between growing cycles. In Minneola, the PS increased 35 \% from 2013 to 2015, while in C35 and Amblycarpa, it decreased $7 \%$ over the same period. The fruit production cycle did not affect the number of embryos per seed for most genotypes. Minneola was an exception, possibly due to its genetic load (Andrade-Rodríguez et al., 2004; Kishore et al., 2012; Soares-Filho et al., 1995). Consequently, the differences observed between researchers might result from various factors such as crop management, pollination, seed development, genotype (genera and species), as polyembryony observations for more than ten years in

Table 2 - Characteristics of citrus polyembryony seed in five citrus cultivars sampled during the 2013-2014 and 2014-2015 fruit growing cycles.

\begin{tabular}{lcccc}
\hline Cultivars & Harvest & $P$ & NE & PEC \\
\hline \multirow{2}{*}{ C35 Citrange } & $2013-2014$ & $83.0 \mathrm{~b}$ & $3.9 \mathrm{a}$ & \multirow{2}{*}{93} \\
& $2014-2015$ & $90.0 \mathrm{a}$ & $4.0 \mathrm{a}$ & \\
\hline \multirow{2}{*}{ Volkamer Lemon } & $2013-2014$ & $88.0 \mathrm{a}$ & $3.6 \mathrm{a}$ & \multirow{2}{*}{100} \\
\hline Amblycarpa & $2014-2015$ & $83.0 \mathrm{a}$ & $2.7 \mathrm{a}$ & \\
Mandarin & $2013-2014$ & $88.0 \mathrm{~b}$ & $4.6 \mathrm{a}$ & \multirow{2}{*}{93} \\
\hline \multirow{2}{*}{ Valencia Orange } & $2014-2015$ & $95.0 \mathrm{a}$ & $5.2 \mathrm{a}$ & \\
\hline \multirow{2}{*}{ Minneola Tangelo } & $2013-2014$ & $98.0 \mathrm{a}$ & $4.4 \mathrm{a}$ & \multirow{2}{*}{87} \\
& $2014-2015$ & $93.0 \mathrm{a}$ & $4.6 \mathrm{a}$ & \\
\hline
\end{tabular}

$\mathrm{P}=$ Polyembryony percentages, $\mathrm{NE}=$ number of embryos per seed, $\mathrm{PEC}$ $=$ percentage of large embryos located in the chalaza. Means with different letters per cultivar in a column are statistically different, according to the nonparametric Mann-Whitney test $(p \leq 0.05)$.

Table 3 - Seedlings (sample size $=20$ ) obtained from the largest embryo per seed identified as different from the female parent by simple sequence repeats (SSR) primers in five citrus cultivars.

\begin{tabular}{|c|c|c|c|}
\hline \multirow[t]{2}{*}{ Cultivars } & \multirow[t]{2}{*}{$\begin{array}{l}\text { Seedlings different from the } \\
\text { female parent }\end{array}$} & \multicolumn{2}{|c|}{$\begin{array}{c}\text { Molecular primer (allele size on par bases) with polymorphism information } \\
\text { content (PIC) values greater than } 0.5\end{array}$} \\
\hline & & CCSM4 (87-125) & F4 (150-162) \\
\hline \multirow[t]{2}{*}{ C35 Citrange } & \multirow[t]{2}{*}{$6(30 \%)$} & CCSM13 (72-83) & F6 (137-162) \\
\hline & & CCSM18 (202-275) & F7 (93-105) \\
\hline \multirow{4}{*}{ Volkamer Lemon } & \multirow{4}{*}{$9(45 \%)$} & CAT01 (137-200) & F11 (138-173) \\
\hline & & CCSM13 (72-83) & GT03 (150-210) \\
\hline & & CCSM147(113-123) & TAA41 (137-195) \\
\hline & & & F4 (150-162) \\
\hline \multirow{2}{*}{ Amblycarpa Mandarin } & \multirow{2}{*}{$3(15 \%)$} & TAA1 (162-178) & TAA45 (131-143) \\
\hline & & TAA41 (137-195) & \\
\hline \multirow{2}{*}{ Valencia Orange } & \multirow{2}{*}{$3(15 \%)$} & AG14 (137-190) & ATC09 (177-210) \\
\hline & & TAA41 (137-195) & \\
\hline \multirow{4}{*}{ Minneola Tangelo } & \multirow{4}{*}{$9(45 \%)$} & CAT01 (137-200) & F7 (93-105) \\
\hline & & CCSM4 (90-120) & F11 (138-173) \\
\hline & & F2 (137-166) & TAA41 (137-195) \\
\hline & & F4 (150-162) & TAA52 (84-120) \\
\hline
\end{tabular}

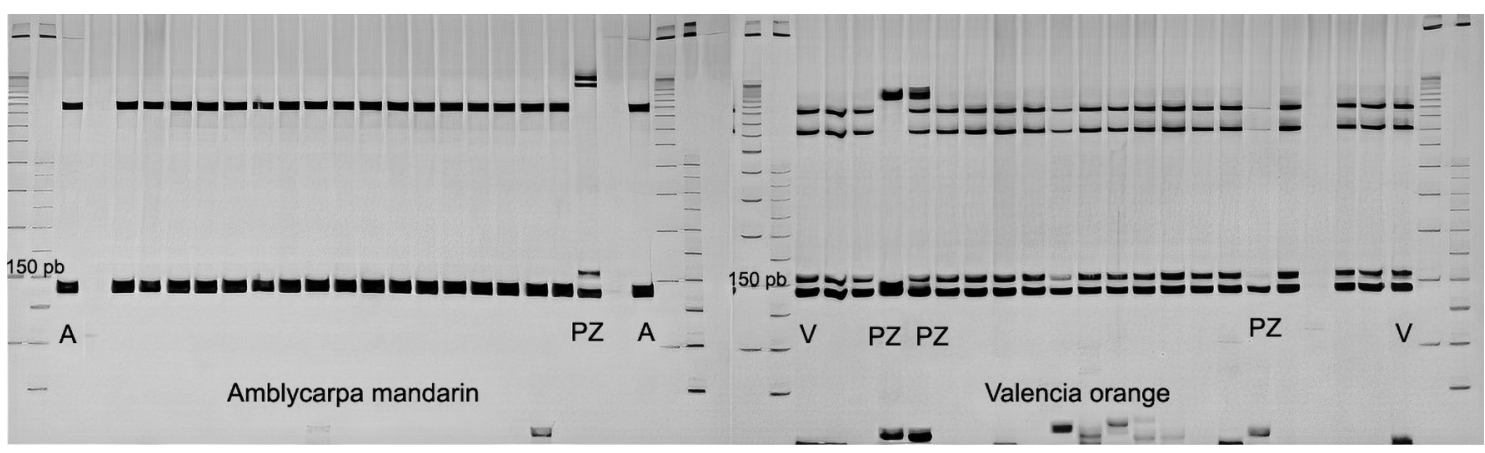

Figure 2 - Microsatellite F4 alleles banding pattern (150-162 base pair, bp) on 14 \% polyacrylamide gel, 50 and 25 bp molecular size markers; $\mathrm{A}=$ Amblycarpa mandarin female parent; $\mathrm{V}=$ Valencia orange female parent; $\mathrm{PZ}$ = Seedling different from the female parent. 
Table 4 - Genotype similarity index (GSI) values between seedlings obtained from the largest embryo end the female parent in five polyembryonic citrus cultivars. GSI was calculated with 30 simple sequence repeats (SSR) primers.

\begin{tabular}{|c|c|c|c|c|c|}
\hline \multirow{3}{*}{ Replication } & \multicolumn{5}{|c|}{ Cultivars } \\
\hline & $\begin{array}{c}\text { C35 } \\
\text { Citrange }\end{array}$ & $\begin{array}{c}\text { Volkamer } \\
\text { Lemon }\end{array}$ & $\begin{array}{l}\text { Amblycarpa } \\
\text { Mandarin }\end{array}$ & $\begin{array}{l}\text { Valencia } \\
\text { Orange }\end{array}$ & $\begin{array}{c}\text { Minneola } \\
\text { Tangelo }\end{array}$ \\
\hline & GSI & GSI & GSI & GSI & GSI \\
\hline 1 & 0.94 & 0.76 & 1.00 & 0.99 & 0.88 \\
\hline 2 & 0.95 & 0.71 & 0.99 & 0.74 & 0.85 \\
\hline 3 & 0.99 & 0.97 & 0.98 & 0.71 & 0.99 \\
\hline 4 & 0.86 & 0.99 & 0.99 & 0.93 & 0.76 \\
\hline 5 & 0.87 & 0.96 & 0.99 & 1.00 & 0.81 \\
\hline 6 & 1.00 & 0.97 & 0.98 & 0.99 & 0.95 \\
\hline 7 & 0.95 & 0.87 & 0.99 & 0.96 & 0.95 \\
\hline 8 & 0.98 & 0.91 & 0.98 & 1.00 & 0.98 \\
\hline 9 & 0.86 & 1.00 & 0.97 & 1.00 & 0.77 \\
\hline 10 & 0.84 & 1.00 & 0.98 & 1.00 & 0.97 \\
\hline 11 & 0.99 & 0.96 & 0.98 & 1.00 & 0.88 \\
\hline 12 & 1.00 & 0.97 & 0.97 & 1.00 & 0.79 \\
\hline 13 & 0.97 & 0.78 & 0.99 & 1.00 & 0.80 \\
\hline 14 & 0.98 & 0.82 & 0.99 & 0.99 & 1.00 \\
\hline 15 & 0.94 & 0.96 & 0.85 & 1.00 & 0.99 \\
\hline 16 & 0.98 & 0.96 & 1.00 & 0.99 & 1.00 \\
\hline 17 & 0.98 & 0.88 & 0.99 & 0.96 & 0.99 \\
\hline 18 & 0.99 & 0.91 & 0.99 & 1.00 & 1.00 \\
\hline 19 & 1.00 & 0.96 & 0.79 & 1.00 & 0.80 \\
\hline 20 & 1.00 & 0.94 & 0.81 & 0.99 & 0.99 \\
\hline $\begin{array}{l}\text { Nucellar } \\
\text { seedlings }\end{array}$ & $70 \%$ & $55 \%$ & $85 \%$ & $85 \%$ & $55 \%$ \\
\hline
\end{tabular}

aGSI values $\geq 0.95$.

citrus and mango have revealed (Andrade-Rodríguez et al., 2004, 2005; Martínez-Ochoa et al., 2012).

Studies on immature seeds have shown that the endosperm promotes embryo development near the micropyle end. Similarly, nucellar embryo growth is favored as it starts earlier (Koltunow et al., 1995; Wakana and Uemoto, 1988). Consequently, the largest embryo in the seed should be the one that developed earliest. The largest embryo in each seed was located at the chalaza in at least $87 \%$ of the cases. By considering the location (Table 3) and the asexual origin (Table 4), we identified that $65 \%$ of the embryos in the chalaza were nucellar in C35 citrange, $55 \%$ in Volkamer lemon, $79 \%$ in Amblycarpa mandarin, $74 \%$ in Valencia orange and $51 \%$ in Minneola tangelo. Therefore, the chalaza is not an indicator of the location of the nucellar embryo.

\section{Identification of nucellar seedlings when derived from the largest embryo}

From previous experiences on molecular marking (Andrade-Rodríguez et al., 2005; Martínez-Ochoa et al., 2012), we used 30 microsatellites (Barkley et al., 2006; Kijas et al., 1997; Novelli et al., 2006; Rao et al., 2008) associated to the GSI analytical-method to identify seedlings derived from the nucella.
Our results showed that 17 SSRs were the most useful molecular markers for detecting nucellar seedlings in citrus plants and identifying polymorphism levels depending on the number of seedlings that were different from the female parent (Table 3). TAA41 was the most informative primer for identifying seedlings different from the female parent in the five cultivars studied (orange, lemon, mandarin, tangelo, and citrange). However, previous research classified this primer as poorly informative for several citrus crosses (CarrilloMedrano et al., 2018; Yildiz et al., 2013). Therefore, only one SSR primer or a small primer set is insufficient for determining the embryo sexual origin in different citrus cultivars.

In this research study, we evaluated only the plant produced by the largest embryo in each seed, whereas other authors have evaluated all the embryos from the seed (Novelli et al., 2006; Rao et al., 2008; CarrilloMedrano et al., 2018). Consequently, we measured plants related to the embryo that gave rise to them. Instead, Rao et al. (2007) used expressed sequence tagderived simple sequence repeat markers (EST-SSRs) to differentiate hybrids of $C$. reticulata Blanco x $C$. maxima (Burm.) Merr., by planting whole seeds with all their embryos.

Out of 204 hybrids, they identified $73 \%$ as zygotic. The use of morphological markers (for trifoliate leaf), Soares-Filho et al. (2000) recognized $39 \%$ of zygotic plants from large embryos $(\geq 5 \mathrm{~mm})$ in the 'Sunki tangerine; however, these authors did not separate the individual embryos of each seed, since they studied a set of large embryos. In our study individual evaluations of each embryo and its sexual origin allowed us to generate reliable conclusions related to location, size and the probability of nucellar embryo origin only of viable embryos capable of producing seedlings.

One specific band (either by presence or absence) indicated a polymorphism in our study. The polymorphisms observed in SSRs derived from differences in the number of repeats of the motif caused by polymerase strand-slippage in DNA replication or by recombination errors (Carneiro et al., 2016). Furthermore, different alleles may exist at an SSR locus (mutations that may have evaded correction by the DNA mismatch repair system), implying that SSRs are more informative per locus than other molecular markers, including single nucleotide polymorphisms (SNPs) (Carneiro et al., 2016). Consequently, we considered an SSR polymorphism a marker good enough to differentiate the female parent from identical or different seedlings.

On the other hand, high seedling homogeneity (uniformity) is necessary as the rootstock might affect the grafted cultivar development (Andrade-Rodríguez et al., 2004; Passos et al., 2006). Therefore, it is essential to determine the type of seedlings, nucellar or zygotic, originating from seeds on a commercial scale (Passos et al., 2006). In previous studies on citrus polyembryony, researchers have claimed a preference for polyembryonic 
rootstocks for apomictic propagation. For example, for $C$. reshni evaluated across three cycles, AndradeRodríguez et al. (2005) estimated between 79 and $90 \%$ of polyembryonic seeds and $83 \%$ of nucellar seedlings. On the other hand, for C. volkameriana rootstock, García et al. (1999) reported that only $78 \%$ of nucellar seedlings derived from open-pollinated seeds, while we registered $55 \%$ nucellar seedlings for the same citrus species. In the 2014-2015 season, all the cultivars had more than $83 \%$ of polyembryony (Table 2). However, only Amblycarpa mandarin and Valencia orange had high levels of apomictic propagation with $85 \%$ of nucellar embryos (Table 4).

Our results show the high probability of reproducing plants different from the female parent (not nucellar plants) from the LE from seeds of the five polyembryonic citruses studied. Considering that the percentage of plants different from the female parent ranged between $15 \%$ and $45 \%$, vegetative propagation could only be achieved by selecting nucellar plants utilizing molecular markers. Therefore, future research on citrus polyembryony should explore the relationship between the origin of the individual embryo with its size and position in the seed. Such information might provide insights into the probability embryos in positions $2,3,4$, 5,6 , and 7 (Figure 1) have for nucellar plant propagation.

\section{Acknowledgments}

The authors thank Postgraduate College and Autonomous Chapingo University for the facilities made available during the study. We also thank Vivero Cazones for providing the plant material and plant care help. This work was supported by the National Council of Science and Technology of Mexico (326603, 2016).

\section{Authors' Contributions}

Conceptualization: Martínez-Ochoa, E.C.; VillegasMonter, A.; Alarcón-Zúñiga, B. Data acquisition: Martínez-Ochoa, E.C.; Villegas-Velázquez, I.; Data analysis: Martínez-Ochoa, E.C.; Villegas-Monter, A.; Alarcón-Zúñiga, B; González-Hernández, V.A.; Design of methodology: Martínez-Ochoa, E.C.; VillegasMonter, A.; Alarcón-Zúñiga, B.; Villegas-Velázquez, I.; Writing and editing: González-Hernández, V.A.; Martínez-Ochoa, E.C.; Villegas-Monter, A.; VillegasVelázquez, I.

\section{References}

Aleza, P.; Juárez, J.; Ollitrault, P.; Navarro, L. 2010. Polyembryony in non-apomictic citrus genotypes. Annals of Botany 106: 533545. https://doi.org/10.1093/aob/mcq148

Andrade-Rodríguez, M.; Villegas, A.; Carrillo, G.; García, A. 2004. Polyembryony and identification of Volkamer lemon zygotic and nucellar seedlings using RAPD. Pesquisa Agropecuária Brasileira 39: 551-559. https://doi.org/10.1590/ S0100-204X2004000600006
Andrade-Rodríguez, M.; Villegas-Monter, A.; Gutiérrez, MA.; Carrillo, G.; García, A. 2005. Polyembryony and RAPD markers for identification of zygotic and nucellar seedlings in Citrus. Agrociencia 39: 371-383.

Bastianel, M.; Schwarz, S.F.; Coleta, F.H.D.; Lin, L.L.; Machado, M.; Koller, O.C. 1998. Identification of zygotic and nucellar tangerine seedlings (Citrus spp.) using RAPD. Genetics and Molecular Biology 21. https://doi.org/10.1590/S141547571998000100020

Barkley, N.A.; Roose, M.L.; Krueger, R.R.; Federici, C.T. 2006. Assessing genetic diversity and population structure in Citrus germplasm collection utilizing simple sequence repeat markers (SSRs). Theoretical and Applied Genetics 112: 15191531. https://doi.org/10.1007/s00122-006-0255-9

Carrillo-Medrano, S.H.; Gutierrez-Espinosa, M.A.; RoblesGonzalez, M.M.; Cruz-Izquierdo, S. 2018. Identification of Mexican lime hybrids by SSR molecular markers. Revista Mexicana de Ciencias Agrícolas 1: 11-23 (in Spanish with abstract in English).

Carneiro, V.M.L.; Santini L.; Lima, D.A.; Freitas, M.C. 2016. Microsatellite markers: what they mean and why they are so useful. Genetics and Molecular Biology 39: 312-328.

DeWoody, A.; Honeycutt, R.L.; Skow, L.C. 1995. Microsatellite markers in white-tailed deer. Journal of Heredity 86: 317-319.

Duarte, F.E.V.O.; Barros, D.D.R.; Girari, E.A.; Soares-Filho, W.D.S.; Passos, O.S. 2013. Polyembryony and morphological seed traits in citrus rootstocks. Revista Brasileira de Fruticultura 35: 246-254. https://doi.org/10.1590/S010029452013000100028 (in Portuguese, with abstract in English).

García, R.M.J.; Asins, M.J.; Forner, J.; Carbonell, E.A. 1999. Genetic analysis of apomixis in Citrus and Poncirus by molecular markers. Theoretical and Applied Genetics 99: 511-518.

Holland, J.B. 2006. Estimating genotypic correlations and their standard errors using multivariate restricted maximum likelihood estimation with SAS Proc MIXED. Crop Science 46: 642-654. https://doi.org/10.2135/cropsci2005.0191

Kijas, J.M.H.; Thomas, M.R.; Fowler, J.C.S.; Roose, M.L. 1997. Integration of trinucleotide microsatellites into a linkage map of Citrus. Theorical Applied of Genetics 94: 701-706. https:// doi.org/10.1007/s001220050468

Kishore, K.; Monika, N.; Rinchen, D.; Lepcha, B.; Pandey, B. 2012. Polyembryony and seedling emergence traits in apomitic citrus. Scientia Horticulturae 138: 101-107. https:// doi.org/10.1016/j.scienta.2012.01.035

Koltunow, A.M.; Soltys, K.; Nito, N.; McClure, S. 1995. Anther, ovule, seed, and nucellar embryo development in Citrus sinensis cv. Valencia. Canadian Journal of Botany 73: 15671582. https://doi.org/10.1139/b95-170

Mannen, H.; Tsuji, S.; Mukai, F.; Goto, N.; Ohtagaki, S. 1993. Genetic similarity using DNA fingerprinting in cattle to determine relationship coefficient. Journal of Heredity 84: 166-169.

Martínez-Ochoa, E.C.; Andrade, R.M.; Rocandio, R.M.; Villegas, M.A. 2012. Identification of zygotic and nucellar seedlings in polyembryonic mango cultivars. Pesquisa Agropecuária Brasileira 47: 1629-1636. https://doi.org/10.1590/S0100204X2012001100010 
Novelli, V.M.; Cristofani, M.A.; Souza, A.; Machado, M.A. 2006. Development and characterization of polymorphic microsatellite markers for the sweet orange (Citrus sinensis L. Osbeck). Genetics and Molecular Biology 29: 90-96. https:// doi.org/10.1590/S1415-47572006000100018

Passos, O.S.; Peixoto, L.S.; Santos, L.C.; Caldas, R.; Soares-Filho, W.D.S. 2006. Characterization of Poncirus trifoliata hybrids and other citrus rootstocks in the State of Bahia. Revista Brasileira de Fruticultura 28: 410-413. https://doi.org/10.1590/S010029452006000300016 (in Portuguese, with abstract in English).

Rao, M.N.; Soneji, J.R.; Chen, C.; Choi, Y.A.; Huang, S.; Gmitter, F.G. 2007. Identification of zygotic and nucellar seedlings from citrus rootstock candidates using RAPD. Acta Horticulturae 738: 255-260. https://doi.org/10.17660/ActaHortic.2007.738.25

Rao, M.N.; Soneji, J.R.; Chen, C.; Huang, S.; Gmitter, F.G. 2008. Characterization of zygotic and nucellar seedlings from sour orange like citrus rootstock candidates using RAPD and ESTSSR markers. Tree Genetics \& Genomes 4: 113-124. https://doi. org/10.1007/s11295-007-0092-2

Ribeiro, V.G.; Pasqual, M.; Ramos, J.D.; Bearzoti, E.; D'Angelo Neto, S. 1999. Embryo development stage and the location of embryo zygotic in the seed of citrine. Pesquisa Agropecuária Brasileira 34: 1327-1333. https://doi.org/10.1590/S0100204X1999000800002 (in Portuguese, with abstract in English).

Ruiz, C.; Paz, M.B.; Asíns, M.J. 2000. A quick methodology to identify sexual seedlings in citrus breeding programs using SSR markers. Euphytica 112: 89-94. https://doi.org/ 10.1023/A:1003992719598
Soares-Filho, W.D.S.; Lee, M.L.; Cunha-Sobrinho, A.P. 1995. Influence of pollinators on polyembryony in citrus. Acta Horticulturae 403: 857-864.

Soares-Filho, W.D.S.; Moreira, C.S.; Cunha, M.A.P.; CunhaSobrinho, A.P.; Passos, O.S. 2000. Polyembryony and hybrids frequency in Citrus spp. Pesquisa Agropecuária Brasileira 35: 857-864. https://doi.org/10.1590/S0100-204X2000000400025 (in Portuguese, with abstract in English).

Sudheer, P.D.V.; Nirali, P.; Reddy, M.P.; Radhakrishnan, T. 2008. Comparative study of interspecific genetic divergence and phylogenic analysis of genus Jatropha by RAPD and AFLP. Molecular Biology Reproduction 36: 901-907. https://doi. org/10.1007/s11033-008-9261-0

Wakana, A.; Uemoto, S. 1988. Adventive embryogenesis in Citrus (Rutaceae). II. Postfertilization development. American Journal of Botany 75: 1033-1047.

Wu, R.L.; Ma, C.X.; Casella, G. 2007. Statistical Genetics of Quantitative Traits: Linkage, Maps and QTL. Springer, New York, NY, USA.

Yildiz, E.; Kaplankiran, M.; Demirkeser, T.H.; Uzun, A.; Toplu, C. 2013. Identification of zygotic and nucellar individuals produced from several citrus crosses using SSRs markers. Notulae Botanicae Horti Agrobotanici Cluj-Napoca 41: 478484. https://doi.org/10.15835/nbha4129037 